\title{
Hypothesis on the dual origin of the mammalian subplate
}

\author{
Juan F. Montiel ${ }^{1,2 *}$, Wei Zhi Wang ${ }^{1}$, Franziska M. Oeschger ${ }^{1}$, Anna Hoerder-Suabedissen ${ }^{1}$, Wan Ling Tung ${ }^{1}$, \\ Fernando García-Moreno ${ }^{1}$, Ida Elizabeth Holm ${ }^{3}$, Aldo Villalón ${ }^{2}$ and Zoltán Molnár ${ }^{*}$ * \\ Department of Physiology, Anatomy and Genetics, University of Oxford, Oxford, UK \\ 2 Center for Biomedical Research, Faculty of Medicine, Diego Portales University, Santiago, Chile \\ ${ }^{3}$ Department of Pathology, Randers Hospital, Randers and Clinical Institute, University of Aarhus, Aarhus, Denmark
}

\section{Edited by:}

Luis Puelles, Universidad de Murcia,

Spain

\section{Reviewed by:}

Heiko J. Luhmann, Institut für

Physiologie und Pathophysiologie,

Germany

Patrick O. Kanold, University of

Maryland, USA

\section{*Correspondence:}

Juan F. Montiel, Faculty of Medicine,

Diego Portales University, Av. Ejército

141, Santiago, Chile.

e-mail: juan.montiel@udp.cl;

Zoltán Molnár, Department of

Physiology, Anatomy and Genetics,

University of Oxford, Le Gros Clark

Building, South Parks Road, Oxford

OX1 30X, UK.

e-mail:zoltan.molnar@dpag.ox.ac.uk
The development of the mammalian neocortex relies heavily on subplate. The proportion of this cell population varies considerably in different mammalian species. Subplate is almost undetectable in marsupials, forms a thin, but distinct layer in mouse and rat, a larger layer in carnivores and big-brained mammals as pig, and a highly developed embryonic structure in human and non-human primates. The evolutionary origin of subplate neurons is the subject of current debate. Some hypothesize that subplate represents the ancestral cortex of sauropsids, while others consider it to be an increasingly complex phylogenetic novelty of the mammalian neocortex. Here we review recent work on expression of several genes that were originally identified in rodent as highly and differentially expressed in subplate. We relate these observations to cellular morphology, birthdating, and hodology in the dorsal cortex/dorsal pallium of several amniote species. Based on this reviewed evidence we argue for a third hypothesis according to which subplate contains both ancestral and newly derived cell populations. We propose that the mammalian subplate originally derived from a phylogenetically ancient structure in the dorsal pallium of stem amniotes, but subsequently expanded with additional cell populations in the synapsid lineage to support an increasingly complex cortical plate development. Further understanding of the detailed molecular taxonomy, somatodendritic morphology, and connectivity of subplate in a comparative context should contribute to the identification of the ancestral and newly evolved populations of subplate neurons.

Keywords: subplate, cerebral cortex evolution, chick, turtle, Monodelphis domestica, pig, human

\section{INTRODUCTION}

The subplate was first described in the human cortex (Kostović and Molliver, 1974), in the fetal macaque (Rakic, 1977), rat (Rickmann et al., 1977), and then in carnivores (Luskin and Shatz, 1985). It was defined as a transient zone below the cortical plate and above the intermediate zone in the developing cortex (Rakic, 1977; Bystron et al., 2008). The developing subplate zone contains residential subplate cells, and numerous other migrating cells and extending fibers through the region. Subplate cells initially contribute to the preplate that is then split into the subplate and marginal zone by the subsequent arrival of cortical plate cells (Marín-Padilla, 1971). Subplate has received renewed attention because of its functional relevance in cerebral cortex development (Ayoub and Kostović, 2009). During the last decades, the knowledge about subplate has been extended to include functional and molecular properties pointing to a structure with heterogeneous cell populations and a highly dynamic ontogeny (Antonini and Shatz, 1990; Hoerder-Suabedissen et al., 2009; Oeschger et al., 2010). There are several novel markers for subplate cells in the murine cortex and we recently explored the comparative expression of these in different amniotes (Wang et al., 2011). We consider species with critical phylogenetic relations (Figure 1) to approach different comparative issues related to phylogenetic origin, species-specific differences, and the proportions of this structure in rodents, marsupials, and primates. The aim of this review is to evaluate recent evidence to speculate on the possible phylogenetic origin and evolution of this structure.

\section{MULTIPLE FUNCTIONS OF SUBPLATE NEURONS DURING CORTICAL DEVELOPMENT}

Subplate neurons play different roles at different periods of cortical development. At early stages, subplate neurons are involved in thalamo-cortical axon pathfinding at the level of the initial areal targeting and pioneer the corticofugal pathway (Ghosh et al., 1990; Allendoerfer and Shatz, 1994; Molnár and Blakemore, 1995; Catalano and Shatz, 1998; López-Bendito and Molnár, 2003). Later, they play a role in the eventual innervation of cortical layer IV by thalamic afferents and the establishment of optical orientation columns (Kanold et al., 2003). They are also necessary for the maturation of inhibition in cortical layer IV in areas innervated by the thalamus (Kanold and Shatz, 2006), and drive oscillations in the gap junction coupled early cortical syncytium (Dupont et al., 2006). During development, subplate neurons are electrically active and capable of firing action potentials (Luhmann et al., 2000; Hanganu et al., 2001; Moore et al., 2009) while incorporating, at least transiently, into the cortical and subcortical circuitry (McConnell et al., 1989; Friauf and Shatz, 1991; Higashi et al., 2002, 2005; Kanold et al., 2003; Piñon et al., 2009; Zhao et al., 2009). Subplate neurons in culture are triggered to a rapid induction of synapses when are exposed to neuron and glia cells (McKellar and Shatz, 2009). For a recent review on developmental and functional properties of subplate (see Kanold and Luhmann, 2010). 


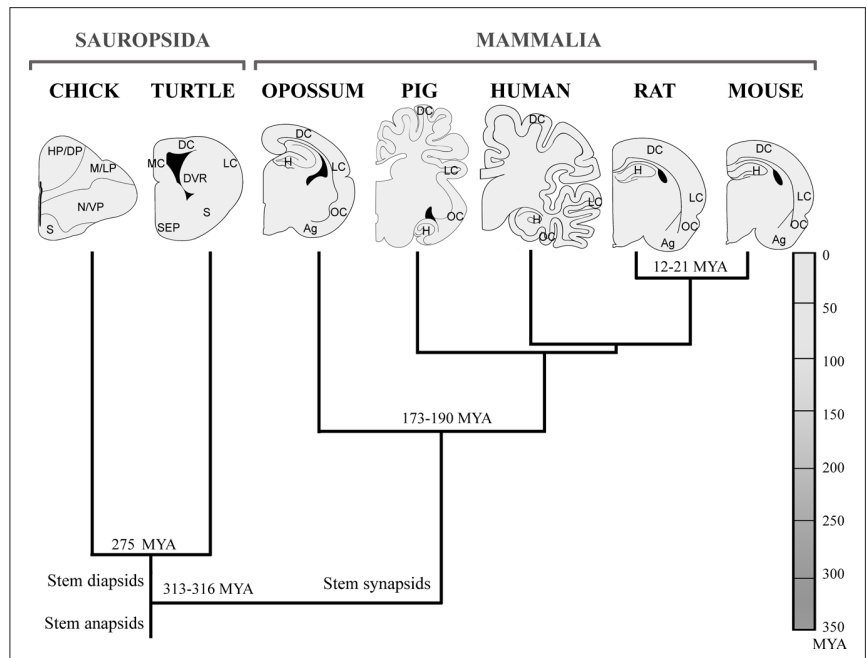

FIGURE 1 | Cladogram of the species investigated with subplate murine markers defined by fossil record, nuclear and mitochondrial DNA sequence data. This is based on previous literature (Carroll, 1988; Mannen and Li, 1999; Rieppel and Reisz, 1999; Zardoya and Meyer, 2001; Gibbs et al., 2004; Pereira and Baker, 2006). Amniotes group is early subdivided into sauropsids (reptiles and birds) and mammals, both lines are represented in analyzed species. The brains of mammals and sauropsids, sketched in coronal sections, are morphologically very different, although being organized according to a common basic plan, which is more evident at developmental stages. Ag, amygdala; DC, dorsal cortex; DP, dorsal pallium; DVR, dorsal ventricular ridge; $H$, hippocampus; $H P$, hyperpallium; LC, lateral cortex; LP, lateral pallium; M, mesopallium; MC, medial cortex; N, nidopallium; OC, olfactory cortex; S, striatum; SEP, septum; VP, ventral pallium (ii) In contrast, the "ancestral subplate" hypothesis suggests that subplate neurons were already present in the common ancestor of mammals and sauropsids. Usually, this is taken in a broader sense - the origin of all infragranular layers, including the subplate, is shared between the sauropsid and mammalian lineages. This hypothesis thus implies that the granular and supragranular mammalian neurons are a recent addition in neocortical phylogeny.

Based on similarities in gene expression patterns between the subventricular zone (SVZ) progenitor cells and the supragranular cortical neurons, it has been suggested that SVZ progenitors generate the upper layers of the cerebral cortex (Tarabykin et al., 2001). Comparative analysis of the cortical progenitor populations in the ventricular and SVZs revealed the absence of a SVZ in the dorsal cortex of sauropsids in contrast to all studied mammals and this might be related to the absence of the supragranular cell populations (Kriegstein et al., 2006; Molnár et al., 2006; Cheung et al., 2007, 2010).

Additionally, there is evidence for similarity of infragranular layers of the neocortex and the dorsal cortex of turtle, based on shared gene expression, presence of neurotransmitters, and equivalence of Golgi stained cell morphologies (Marín-Padilla, 1971; Reiner, 1991; Aboitiz et al., 2005). Along the same line, it has been suggested that a preplate is present during the development of the dorsal cortex in reptiles (Nacher et al., 1996), indicating that the subplate originated as an embryonic structure before the appearance of the neocortex and the inversion of the cortical neurogenetic gradient observed in mammals.

(iii) A third hypothesis would combine the above two and suggest that subplate in mammals is comprised of both new and ancestral cell populations. This interpretation implies that an embryonic subplate was present in an ancestral mammal, but additional populations evolved as cortical development and connectivity became more complex. This compelling hypothesis was initially articulated by Aboitiz et al. (2005), but to date there is little persuasive evidence. To test it, one would need to be able to distinguish the ancestral and new populations of subplate cells by birthdating, differential gene expression, or connectivity. Our current review examines some of the recent comparative gene expression analyses and discusses these results in the context of the above hypotheses.

\section{WHAT IS THE EVIDENCE FOR EARLY VS CONTINUOUSLY GENERATED POPULATIONS IN RODENT AND PRIMATE?}

In rodents and carnivores, subplate neurons are generated at the same time as Cajal-Retzius cells in the marginal zone (or future layer I) and prior to the birth of cortical plate neurons (Luskin and Shatz, 1985; Chun and Shatz, 1989). Birthdating studies in rodent revealed that subplate is among the earliest generated and earliest mature cortical neuron populations (Bayer and Altman, 1990). Murine subplate cells are born around embryonic day (E) 11 (Price et al., 1997) just past midway through the mouse gestational period.

In contrast to the rodent subplate, birthdating studies in primates revealed that neurons are continuously added to the subplate until relatively late stages of corticogenesis (Smart et al., 2002; 
Lukaszewicz et al., 2005; Molnár et al., 2006). This notion limits the usefulness of birthdating as an unequivocal method to define and follow subplate neurons in primate based purely on this method.

In human, the subplate zone becomes visible as a cell-poor/ fiber-rich layer situated between the intermediate zone and the cortical plate (Kostović and Rakic, 1990; Meyer, 2007) around 14 postconceptional weeks (PCW), just at the beginning of the second trimester of human gestation. The subplate forms from the merging of the deepest edge of the cortical plate, with an already formed presubplate that contains few neurons but a differentiated neuropil (Mrzljak et al., 1988) and synapses (Kostović and Rakic, 1990). From 14 to 25 PCW in human, large numbers of TBR1+ neurons are continuously added to the subplate zone, which increases in width concurrent with the growth of the cortical plate, with the highest density of cells always found at the border between cortical plate and subplate (Meyer, 2007). Subplate reaches its maximum thickness at the late second and early third trimester. Thereafter the subplate gradually decreases in size and becomes unrecognizable around the sixth postnatal month (Kostović and Rakic, 1990).

\section{ARE SUBPLATE NEURONS TRANSIENT? WHAT IS THE EXTENT OF CELL DEATH IN DIFFERENT SUBPOPULATIONS OF SUBPLATE IN DIFFERENT SPECIES?}

Subplate is generally considered as a largely transient cell population in the developing cortex (Allendoerfer and Shatz, 1994; Kanold and Luhmann, 2010). However, it is not clear to what extent differential cell death is responsible for the dissolution of subplate in different mammalian species. The reported thinning and eventual disappearance could also result from continued migration of transitory cells through this early formed compartment before assimilation into cortical plate (Kostović and Jovanov-Milosević, 2008) and/or the process of brain expansion and the consequent decrease in density in addition to cell death (Luskin and Shatz, 1985; Ghosh et al., 1990; Kostović and Rakic, 1990). Additionally, it is not known whether developmental cell death affects specific cell classes within the subplate or if all subpopulations are equally reduced. At least in the rat, however, it appears that both glutamatergic and GABAergic subplate neuron numbers are decreased to the same extent (Arias et al., 2002).

In a thorough study of pyknotic cell bodies in the developing rat, it was found that the amount of cell death in layer VIb (subplate) was not significantly different from other cortical layers, leading the authors to conclude that cell death does not play any significant role in this species (Valverde et al., 1995). On the other hand, in carnivores and primates, many subplate neurons degenerate under programmed cell death as the cortical plate matures (Wahle and Meyer, 1987; Chun and Shatz, 1989; Kostović and Rakic, 1990; Allendoerfer and Shatz, 1994).

In primates, the surviving subplate cells continue into adult life as interstitial neurons of the white matter (Kostović and Rakic, 1980, 1990; Somogyi et al., 1981; Schiffmann et al., 1988; Chun and Shatz, 1989; Yan et al., 1996). In rat and mouse a considerable proportion of subplate cells persist into adulthood as the anatomically well-defined structure subjacent to the cortex, layer VIb (Lund and Mustari, 1977; Somogyi et al., 1984; Lauder et al., 1986; Huntley et al., 1988; Luskin et al., 1988; Reep and Goodwin, 1988; Winer and Larue, 1989; Cobas et al., 1991; Woo et al., 1991;
Woo and Finlay, 1996; Reep, 2000), and possibly interstitial neurons in the white matter. Reep (2000) has suggested that the presence of a distinct layer VIb/VII in some species relates to the temporal overlap between the development of the subplate and the extension of cortico-cortical axons. The presence of cortico-cortical connections in layer VIb/VII may be thought of as an adult remnant of the excitatory cortical network that is present in the embryonic subplate (Hanganu et al., 2002).

Interestingly, subplate neurons in the primate cortex disappear in different proportions along the depth of subplate/white matter (Kostović and Rakic, 1990). This implies that the persisting subplate neurons in primate are not just random remnants of early born neurons of preplate, but rather seem to belong to a selectively maintained neuronal system with continued function (Kostović et al., 2010). MRI also suggests that there is a regional difference in the loss of subplate as it appears "patchy" in late gestation, both regionally and in relation to the cortical folds, and later can only be seen at the tops of gyri in many brain regions (Perkins et al., 2008).

\section{NOVEL MARKERS FOR SUBPLATE ANALYZED IN SAUROPSIDS AND MAMMALS}

Our previous microarray experiments identified several genes that are specifically expressed in the subplate layer of the mouse dorsal cortex (Hoerder-Suabedissen et al., 2009). These markers are associated to subplate cells, since they change their position in mutants where subplate cells are displaced to the middle (p35 KO) or to the surface of the cortical plate (reeler; Hoerder-Suabedissen et al., 2009).

We selected nuclear receptor-related 1 (Nurr1), monooxygenase Dbh-like 1 (Moxd1), transmembrane protein 163 (Tmem163), complexin 3 (Cplx3), and connective tissue growth factor (Ctgf) and set out to examine the subplate in a comparative context in species that diverge early in the amniote lineage. We studied turtle (Pseudemys scripta elegans), chick (Gallus gallus), gray short-tailed opossum (Monodelphis domestica), mouse (Mus musculus), rat (Rattus norvegicus), and human (Homo sapiens sapiens) at some developing and adult stages (Wang, et al., 2011). For this review we have also included the pig (Sus scrofa domesticus) as a non-primate example of a gyrencephalic, large brain.

While some of these genes are expressed in dorsal pallium in all studied species (Nurr1, Ctgf, Cplx3, and Tmem163), we also observed that closely related mouse and rat differing the expression patterns of other genes (e.g., Moxd1). In embryonic and adult chick brains our selected subplate markers Nurr1, Ctgf, Moxd1, and Tmem 163 are all expressed in pallial regions, mainly in the hyperpallium (dorsal pallium; Figure 2). Murine subplate marker (Nurr1, Ctgf, Moxd1, and Cplx3) genes are expressed in the central cell dense layer of the embryonic and adult turtle dorsal cortex. Although the cytoarchitectonic distinctions are not as apparent in the developing and adult opossum as in rodents, gene expression patterns suggest a widespread subplate population scattered within the lower part of the developing cortical plate (Figure 2). In the embryonic pig, Nurr1 is expressed beneath the cortical plate resembling the highly developed subplate observed in primates (Kostović and Rakic, 1990) and carnivores (McConnell et al., 1989). These findings suggest that subplate populations are present in embryonic and adult stages 


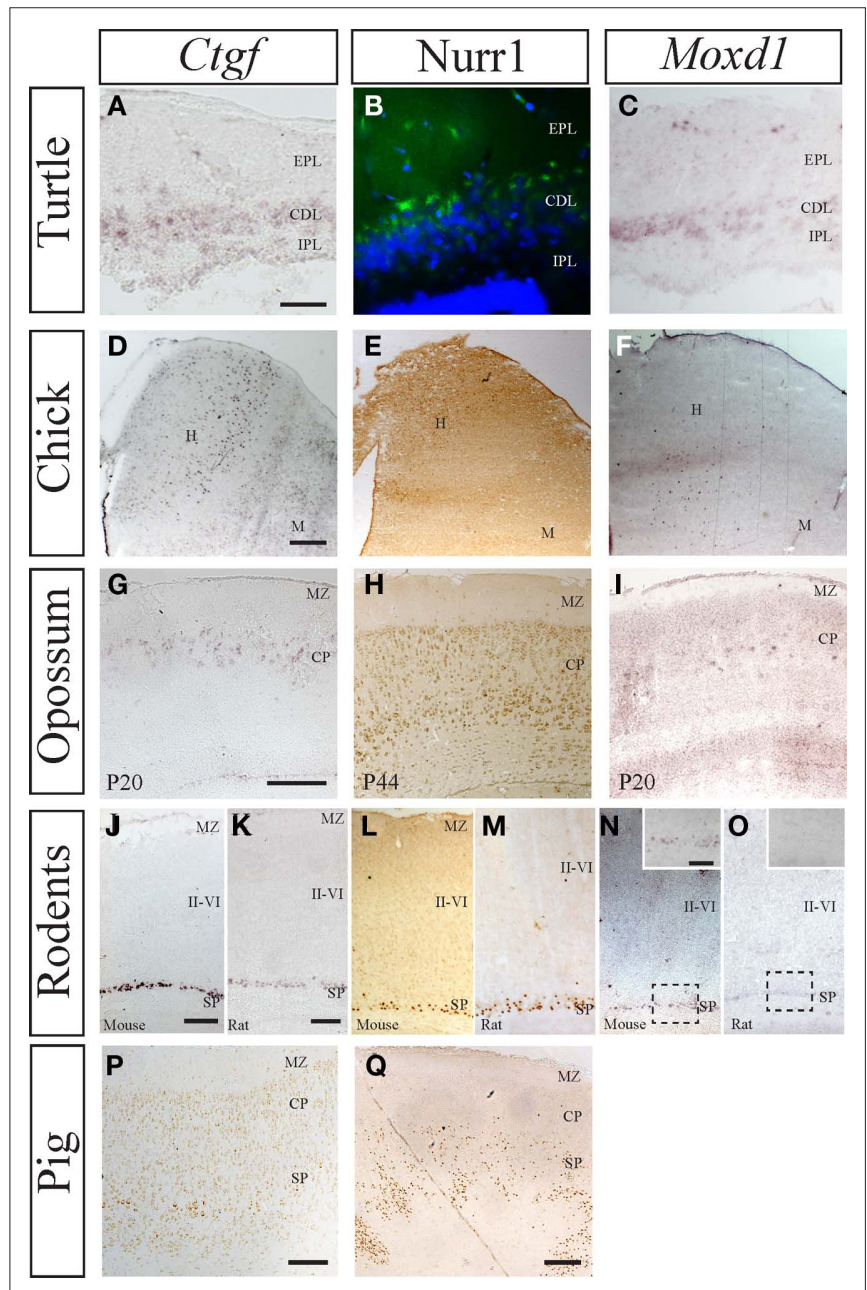

FIGURE 2 | Comparative expression of murine subplate markers (Ctgf, Moxd1, and Nurr1) in selected species. (A-C) mRNA expression of Ctgf and Moxd1 and protein expression of Nurr1 in the adult turtle, with external plexiform layer (EPL), cell dense layer (CDL), and internal plexiform layer (IPL) indicated. All three murine subplate markers are expressed in the dense cell layer in turtle. (D-F) mRNA expression of Ctgf and Moxd1 and protein expression of Nurr1 in chick dorsal pallium with the hyperpallium $(\mathrm{H})$ and Mesopallium (M) indicated. Ctgf is expressed in a column within hyperpallium while Moxd1 labels scattered cells in the hyperpallium, across columnar boundaries. Similarly, Nurr1 is expressed in the dorsal most tip of the hyperpallium, across several columns, but not along their entire depth. (G-I) mRNA expression of Ctgf and Moxd1 and protein expression of Nurr1 in postnatal opossum cortex with cortical plate and marginal zone indicated. Ctgf and Moxd 1 are expressed at in the upper cortical plate at the junction with the marginal zone at P20 while Nurr1 is primarily expressed in the lower cortical plate at P44. (J,K) Protein expression of Ctgf and Nurr1 in the embryonic pig cortex with subplate, cortical plate, and marginal zone indicated. Ctgf protein is localized to a thin band within the subplate, while Nurr1 protein is localized to a thicker band representing the subplate and possibly the lower parts of cortical plate. Nurr1+ cells follow the up and down of the above lying cortical gyri and sulci (at the edges of the image). (L,N,P) mRNA expression of Ctgf and Moxd1 and protein expression of Nurr1 in the postnatal mouse cortex with subplate, layers $\mathrm{II}-\mathrm{VI}$, and marginal zone indicated. All three markers are confined to the subplate zone in mice. $(\mathbf{M}, \mathbf{O}, \mathbf{Q})$ mRNA expression of Ctgf and Moxd1 and protein expression of Nurr1 in postnatal rat cortex with subplate, layers II-VI, and marginal zone indicated. Ctgf and Nurr1 expression is confined to the subplate zone while Moxd1 expression is absent in the rat cortex [see inset in (N) (mouse) and (O) (rat)]. Scale bars $=200 \mu \mathrm{m}$. of both mammals and sauropsids (Wang et al., 2011). Based on our observations, we favor the hypothesis of a dual origin of the subplate cell populations. We propose that some subplate populations were present in the ancestral amniote cortex as originally suggested by Marín-Padilla (1971). However, in mammals the subplate compartment and its cellular constituents continued to evolve and reaching increased levels of complexity, size, and connectivity in species with larger cortices.

The strength of the above gene expression analysis is based on using multiple genes (all of which are expressed in the murine subplate) and analyzing their distribution in diverse species. However, we noted differences even between the closely related mouse and rat, with Moxd1 being absent from the rat subplate (Wang et al., 2011). We are fully aware that the analysis of a marker alone cannot solve the absolute identity of a cell population to recognize its cellular homolog in different species. In support to the comparative utility of these subplate markers, a pairwise comparison of Cplx3, Ctgf, Moxd1, Nurr1, and Tmem163 between rat, opossum, chicken, and human against the mouse protein sequences show a high degree (over $70 \%)$ of amino acidic sequence conservation (Wang et al., 2011). Ideally, gene expression, birthdating, cell morphology, projection pattern, and neurophysiological characteristics should all be linked together in future studies. However, the above results can be used as a starting point to further investigate whether there is extensive overlap in these other categories as well.

\section{ROLE OF SUBPLATE IN THE ESTABLISHMENT OF CORTICO- CORTICAL AND INTRACORTICAL CONNECTIONS}

In primates and carnivores, the subplate achieves its maximal thickness at the time cortico-cortical connections are being developed. Therefore, it has been suggested that in different cortical areas and in different species, the subplate may acquire different thicknesses, in direct relation with cortico-cortical connectivity (Kostović and Rakic, 1990). Additionally, a role for the subplate in directing cortico-cortical axons and in the generation of sulci in gyrencephalic brains was proposed (Kostović and Rakic, 1990), although firm experimental proof for the causal relationships has not been provided. In this context, the pig is an interesting model, as it is evolutionarily more distantly related to humans than mice are; yet its gyrencephalic brain is more similar in terms of size, cytoarchitecture, and duration of corticogenesis (Lind et al., 2007; Nielsen et al., 2010a). Recently, Nielsen et al. (2010b) reported a conserved developmental dynamic and patterning of expression of reelin in pig, which is comparable with rodents and human. We studied the expression pattern of the murine subplate marker Nurrl during embryonic cortical development in pigs (Figure 2) and found a very similar pattern to Nurr1 expression in human (Wang et al., 2010). Others markers like Ctgf and Ddc are also expressed in subplate zone during pig cortical development at E100.

However, a cytoarchitectonically distinct subplate zone, in which subplate cells are aligned separately from cortical plate, does not seem to be necessary for complex cortico-cortical connectivity to arise. In some of the species without a layer VIb/VII in adult stages, like the guinea pig (hystricognath rodent) and phyllostomid bats, there are darkly stained cells in deep layer VI adjacent to the white matter, which give rise to cortico-cortical connections and may 


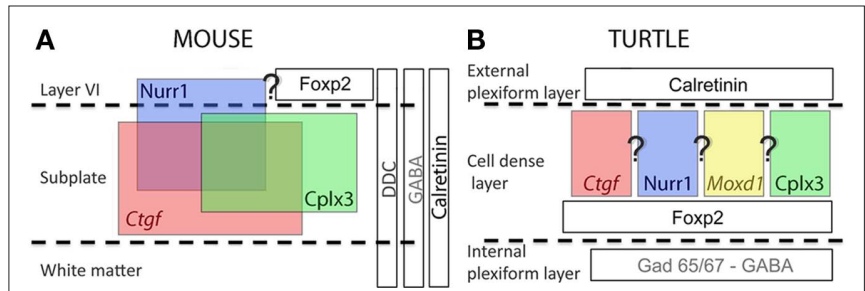

FIGURE 3 | Schematic diagram summarizes the distribution and overlap of several murine subplate cell markers and other neuronal markers in rodents and their distribution in turtle. (A) In early postnatal mouse cerebral cortex Cplx3 and Ctgf are exclusively expressed in subplate cells. Nurr1 has additional expression in layer VI. These markers partially colocalize. Foxp2 is only expressed in layer VI and the overlap with Nurr1 is not yet investigated. Ddc immunoreactive cells are scattered into layer VI and white matter in addition to subplate and do not overlap with either Nurr1 or Cplx3. Calretinin and GABA immunoreactive cells appear in the whole cortical thickness. Neither Cplx3, Ctgf and Nurr1, nor Ddc expressing subplate cells express GABA. (B) In turtle dorsal cortex, the murine SP markers (Cplx3, Ctgf, and Nurr1) and Moxd1 are present at the upper part of the cell dense layer. Unfortunately there is no data about potential colocalization between markers in turtle cortex at present. FoxP2 is expressed below the subplate markers, in the lower part of the cell dense layer. Further, ubiquitous mammalian cortical markers appear restricted to either the internal plexiform layer (GAD65/67 and GABA) or the external plexiform layer (calretinin).
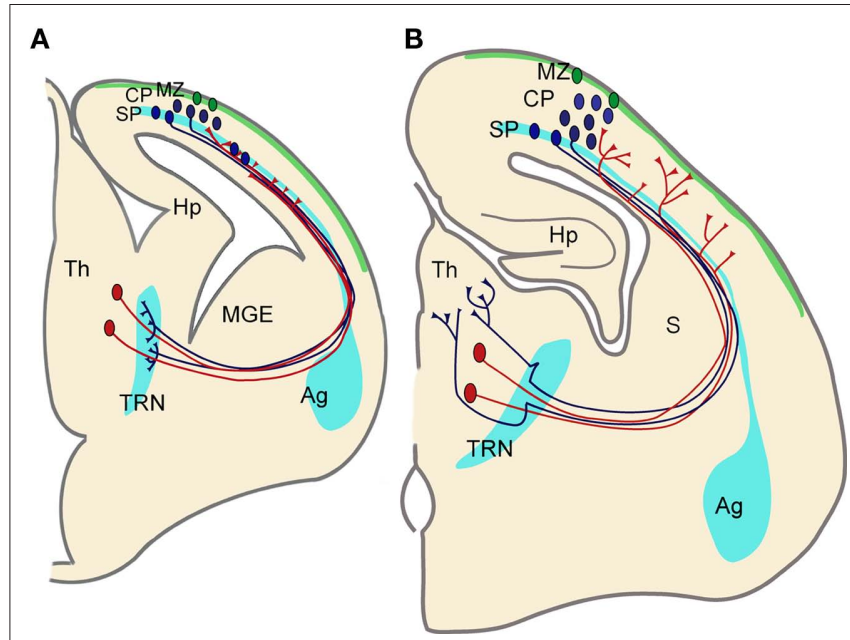

FIGURE 4 | Functional correlation between the developing thalamocortical projections, cortical SP zone, and thalamic reticular nucleus. (A) Corticofugal (blue) and thalamo-cortical (red) axons extend toward each other at early stages during embryonic development and reach close to their targets. However they both stop short of their ultimate targets and corticofugal projections from subplate and layer VI accumulate in the thalamic reticular nucleus (TRN) and thalamo-cortical projections in subplate, respectively. Both compartments contain largely transient cells that get integrated into circuits during these early stages. (B) Toward the middle of the first postnatal week corticofugal and corticopetal axons enter the thalamus (Th) and cortical plate (CP), respectively, where they arborize and establish their contacts with their ultimate targets in thalamus and neocortex. There are signs of fiber decussations in the TRN and in the subplate indicating some rearrangements during development. Pale blue areas (amygdala, subplate, and thalamic reticular nucleus) represent brain regions sharing gene expression patterns. Ag, amygdala; Hp, hippocampus; MGE, medial ganglionic eminence; $\mathrm{MZ}$, marginal zone (green area); S, striatum. be comparable to layer VIb/VII of other animals (Reep, 2000). Nevertheless, no detailed comparative developmental data are available to discard an embryonic subplate role in cortico-cortical connectivity in this species.

\section{COMPARATIVE ASPECTS OF EXTRACORTICAL SUBPLATE PROJECTIONS}

In mammals, subplate neurons develop widespread intra- and extracortical connections including projections to the cortical plate, thalamus, contralateral hemisphere, and colliculus (McConnell et al., 1989; Allendoerfer and Shatz, 1994; Finney et al., 1998). There are species-specific differences in the extent of connectivity. There seems to be a general increase in the number of targets during mammalian phylogeny (Del Rio et al., 2000). Subplate projections are directed to the developing cortical plate providing a substantial glutamatergic input into the maturing cortical plate that has been associated with the establishment of functional cortical modules (McConnell et al., 1989; Friauf et al., 1990; Friauf and Shatz, 1991; Allendoerfer and Shatz, 1994; Finney et al., 1998; Hanganu et al., 2001, 2002; Kanold et al., 2003; Kanold and Shatz, 2006; Piñon et al., 2009). Contrary to carnivores and primates, in rodents the subplate cells do not establish considerable callosal projections to the contralateral cortex (De Carlos and O'Leary, 1992; Ozaki and Wahlsten, 1998; Del Rio et al., 2000). Additionally in carnivores and primates, but not in rodents, subplate neurons project to the superior colliculus (Del Rio et al., 2000).

A phylogenetically conserved connection system in mammals is developed by subplate neurons projecting the earliest fibers into the internal capsule to assist thalamo-cortical pathfinding through the pallial subpallial boundary and then to serve as transient synaptic targets for thalamo-cortical fibers (McConnell et al., 1989; De Carlos and O'Leary, 1992).

\section{CORRELATION BETWEEN SUBPLATE-LIKE NEURONAL POPULATIONS AND THALAMIC AFFERENT TARGETING IN SAUROPSIDS AND MAMMALS}

Subplate enriched gene expression patterns are present in both sauropsids (turtle and chick) and mammals (opossum, rodents, pig, and human; Wang et al., 2010, 2011). In turtles, we observed these cells within the cell dense layer, in chicken in the hyperpallium, in opossum within the deep layers of the neocortex, and in eutherians below the cortical plate. In eutherians, subplate cells have been suggested to be involved in the guidance of thalamic afferents to the dorsal pallium through the pallial subpallial boundary and to provide temporary targets (Molnár and Blakemore, 1995; Hanashima et al., 2006). Displacement of subplate leads to rearrangement of the thalamic ingrowth in mouse mutants (Rakic and Caviness, 1995; Molnár et al., 1998) with functional synapse formation in the altered location (Higashi et al., 2005). Comparative analysis shows similarities in the positional relationship of thalamocortical afferents and the subplate: In reptiles, subplate markers are expressed in the cell dense zone (Figure 3). This more superficial location of subplate-like cell population is mirrored by a tangential and superficial entry of thalamo-cortical afferents through the external plexiform layer to the cortex. Neurons from the cell dense zone, located immediately below to the external plexiform layer, send projections to make contact with this the tangentially arranged 
thalamic afferents (Cordery and Molnár, 1999). Similar, superficial thalamic ingrowth is evidenced also in the reeler and Shaking Rat Kawasaki where the localization of the subplate is next to the marginal zone or in p35-/-, Cdk5-/- mutants where subplate cells are within the cortical plate (Molnár et al., 1998; Higashi et al., 2005; Rakic et al., 2006).

Marsupials, many of which do not have a cytoarchitectonically distinct subplate layer (Harman et al., 1995; Reep, 2000), and insectivores would represent an intermediate evolutionary stage where the thalamic afferents extend in an oblique fashion directly toward the cortical plate or, as it was described in hedgehog, thalamocortical axons arrive to the cortex through both above and below the cortical plate. This organization would be comparable to the p35-/- mutant mouse where the thalamic afferents also ascend to the middle of the cortical plate in oblique fascicles because subplate neurons are displaced there due to migration defects (Rakic et al., 2006; Molnár et al., 2007). In both (marsupial and p35-/- phenotype) the subplate marker distribution does not label a band at the bottom of the cortex as in wild-type mice, but rather labels cells within the cortical plate.

Murine subplate marker expression was also observed in the avian hyperpallium (dorsal pallium; Wang et al., 2011). Cells labeled with the subplate markers were detected in different columns of the hyperpallium, but mainly located in the intercalated hyperpallium area, a recipient of thalamic afferents to the hyperpallium.

These results from mouse mutants and the correlation between subplate marker expression and eventual targeting of thalamocortical axons, imply that subplate-like cellular components may play a fundamental role for the thalamo-cortical organization in both mammals and sauropsids, but not direct evidence for a conserved mechanism has been demonstrated yet.

\section{DEFINING THE CELLULAR CONTENT OF SUBPLATE ZONE DURING DEVELOPMENT}

In mammals, the subplate zone is a highly dynamic compartment in the developing cortex containing both stationary and migrating glutamatergic and GABAergic neurons, various corticopetal and corticofugal projections, glial cells, and blood vessels (Kostović and Rakic, 1990; Allendoerfer and Shatz, 1994; Kanold and Luhmann, 2010).

Subplate neurons have diverse morphologies including inverted pyramidal-like and horizontal cells, as well as polymorphic neurons with different shapes and spiny or smooth dendrites (Kostović and Rakic, 1980, 1990; Valverde et al., 1989).

The simpler organization of the three-laminar visual dorsal cortex of reptiles has been compared to the infragranular layers of the neocortex of mammals in many aspects, including morphology, neurochemistry, and intrinsic and extrinsic connectivity (Reiner, 1991). In general, neurons from the dorsal cortex of turtle could be divided morphologically in two groups of neurons: pyramidal cells corresponding to the main output of the cortex and non-pyramidal or stellate interneurons (Connors and Kriegstein, 1986; Reiner, 1991). The excitatory cells are primarily located in the central cell dense zone. This is also the location of murine subplate marker expression, in agreement with the finding that none of them are co-expressed with GABA in mice. Moreover, a detailed morphological classification of mammalian subplate neurons shows that they share at least five out of six classes of neurons with the reptile cortex: bitufted neurons, pyramidal neurons, inverted pyramidal neurons, multipolar neurons, and candelabra-like monotufted neurons (Hanganu et al., 2002; Luhmann et al., 2009; Srivastava et al., 2009).

\section{GABAergic SUBPLATE NEURONS}

Similarly to other cortical layers there is a population of GABAergic neurons in subplate. These neurons are generally referred to as interneurons because most of them have only local projections. However, several types of GABAergic, so-called interneurons, have an axon that project to distant brain regions to form cortico-cortical synaptic networks (Ribak et al., 1986; Toth and Freund, 1992; Hoerder et al., 2006; Jinno et al., 2007; Tomioka and Rockland, 2007). The GABAergic subplate population express a variety of peptides such as Neuropeptide Y, somatostatin, and cholecystokinin or contain nitric oxide synthase (Wahle and Meyer, 1987; Chun and Shatz, 1989; Meyer et al., 1992; Uylings and Delalle, 1997; Finney et al., 1998; Judas et al., 1999; Torres-Reveron and Friedlander, 2007). In rodents, GABAergic neurons originate from a sector of the subcortical proliferative zone of the ventral telencephalon (subpallium), the ganglionic eminence. From here neurons migrate tangentially into the cortex following several routes to reach their target regions (Parnavelas, 2000; Marín and Rubenstein, 2003). The major stream of tangentially migrating GABAergic neurons is at the border of the intermediate zone and SVZ and smaller streams of migrating cells are present in the subplate and the upper part of marginal zone (Anderson et al., 1997; Pleasure et al., 2000; Molnár et al., 2006; Wonders and Anderson, 2006; Heng et al., 2007; Métin et al., 2007, 2008). This early migration of subpallial inhibitory neurons into the pallium has been observed in all tetrapods, including amphibians (Brox et al., 2003), birds (Cobos et al., 2001), and reptiles (Métin et al., 2007). In the developing lizard brain, Nacher et al. (1996) described the presence of somatostatin-positive cells appearing first in the inner plexiform layer and later in the outer plexiform layer of the medial and dorsal cortices. Cells positive for neuropeptide $Y$ were observed scattered in all regions of the ventral pallium of the turtle (Cordery and Molnár, 1999).

\section{SHARED EXTRACORTICAL GENE EXPRESSION PATTERNS SUGGEST POSSIBLE DEVELOPMENTAL RELATIONS BETWEEN SUBPLATE, CLAUSTRUM, AND AMYGDALA}

Many of our recently identified subplate markers also have strong and specific expression in claustrum (Hoerder-Suabedissen et al., 2009; Wang et al., 2011). A developmental relation between the subplate and other early produced neuronal populations such as the claustrum has been previously emphasized (Swanson, 2000; Künzle and Ratke-Schuller, 2001; Molnár and Butler, 2002).

In some mammals, the persisting subplate cells have an intimate relationship with the claustrum. In the rat, layer VIb/VII merges laterally with the claustrum while in the hedgehog tenrec (insectivora), the adult subplate is embedded within layers of insular and rhinal cortices (Künzle and Ratke-Schuller, 2001). However, in other species, layer VIb/VII is separated from the claustrum (Reep, 2000). Moreover, in some marsupials it has not been possible to observe a subplate, but a claustrum is definitely present in these species (Harman et al., 1995; Künzle and Ratke-Schuller, 2001). In monotremes, a first report communicated the absence of a claustrum (Butler et al., 2002), while a more recent report refuted this 
observation (Ashwell et al., 2004). We found a complex extracortical expression of the subplate marker genes in mammals (opossum, mouse, and rat) that could be explained by the expression of developmental regulatory genes (Medina et al., 2004; Wang et al., 2011). Medina et al. (2004) propose that the claustroamygdalar complex, involving the pallial amygdala (lateral, basolateral, and basomedial amygdala complex) and the claustral complex (claustrum and endopiriform nucleus) derive from the lateral and ventral pallial histogenetic domains. Based on the expression of cadherin 8 and Emx1, the dorsolateral claustrum (claustrum proper), the basolateral amygdalar nucleus, and the posterolateral cortical amygdalar area may be derivatives of rostral or caudal levels of the lateral pallium. Based on the expression of Neurogenin 2 and semaphorin $5 \mathrm{~A}$, the ventromedial claustrum, the endopiriform nuclei, and the anterior and postero-medial cortical amygdalar areas may derive from different rostrocaudal levels of the ventral pallium (Medina et al., 2004). The claustroamygdalar distribution of the studied subplate markers is, at least to some extent, consistent with this line of evidence and with recent comparative data on chick (Medina et al., 2004; Abellán et al., 2009). Ventral pallial cell populations detected by Moxd1 expression in chick could be represented by the Moxd1 cells distributed in the pallial amygdala in mouse (postero-medial cortical amygdaloid nucleus, basomedial nucleus of the amygdala, and lateral amygdaloid nucleus). Tmem163 is expressed in all divisions of the pallium of chick, which represents additional support for the early developmental division between pallial and subpallial territories. In rodents, Tmem163, is expressed in a wide extension of the claustroamygdalar complex, derived from lateral and ventral pallial proliferative regions, and is also expressed in the medial amygdaloid nucleus, posteroventral part of a subpallial derived region. Ctgf is expressed in the ventral part of the mesopallium in chick that could be related to the expression in the claustral complex in rodents. In addition, we found a high expression of Ctgfin the endopiriform nucleus, which is not predicted by a strict correspondence according to Medina et al. (2004). However, the posterior endopiriform nucleus has been proposed to belong to the lateral pallium by other authors (Aboitiz and Montiel, 2007). No lateral or ventral pallial expression of Nurr1 was detected in chick (Wang et al., 2011), and correspondingly, this marker shows a very restricted expression in the claustral complex but not in the amygdala of rodents.

\section{SIMILARITIES WITH THE THALAMIC RETICULAR NUCLEUS; ANOTHER PIONEER NEURON GUIDANCE SYSTEM OF THALAMO-CORTICAL CONNECTIVITY}

We observed diencephalic expression of some of the genes that were enriched in developing subplate (Wang et al., 2011). We found that both Trh and Ddc were expressed in the thalamic reticular nucleus (Wang et al., 2011). This structure has been compared to subplate because it contains largely transient cells, constitutes a temporary target for corticofugal projections and an important waiting

\section{REFERENCES}

Abellán, A., Legaz, I., Vernier, B., Retaux, S., and Medina, L. (2009). Olfactory and amygdalar structures of the chicken ventral pallium based on the combinatorial expression patterns of
LIM and other developmental regulatory genes. J. Comp. Neurol. 516, 166-186.

Aboitiz, F. (1999). Comparative development of the mammalian isocortex and the reptilian dorsal ventricular ridge.

compartment during development (Mitrofanis and Guillery, 1993; Lozsádi et al., 1996; Molnár and Cordery, 1999; Jacobs et al., 2007; Piñon et al., 2009). The thalamo-cortical projections and corticofugal projections get established relatively early during development when the distances are minimal, but then they accumulate/wait in transient cell compartments of the subplate and thalamic reticular nucleus (Shatz and Rakic, 1981; Molnár and Cordery, 1999; Jacobs et al., 2007). Thalamic reticular cells during development have been called the "subplate" of the thalamus (Mitrofanis and Guillery, 1993), and the shared gene expression during development between subplate and thalamic reticular nucleus further supports these claims (Figure 4). It will be important to correlate the exact timing of gene expression patterns with the key developmental steps of the development of the reciprocal thalamo-cortical innervation. A more systematic study with subplate markers that label subplate cells in early development (Oeschger et al., 2010) is now in progress.

\section{CONCLUSION}

We proposed at the beginning of this review, that the subplate is a phylogenetically ancient structure that takes a different form in sauropsids and mammals, particularly in human (Kostović and Rakic, 1990; Wang et al., 2010). We hypothesized that mammalian subplate contains both ancestral and derived elements. This hypothesis is based on our observation that subplate cellular components are not exclusive to mammals; some cell populations expressing the same cohort of genes are also present in sauropsids. In addition, it also takes into account the larger and more complex nature of subplate in mammals with large brains. Evolution of the mammalian cortex required the modification of developmental programs; some of these started to rely on novel populations of subplate neurons possibly characterized by different targets of connectivity. We hypothesize that the derived elements have been modified in the course of mammalian evolution to support an increasingly complex development of the cortical plate (Aboitiz, 1999; Molnár, 2000a,b; Aboitiz et al., 2005). Although this hypothesis is attractive and there is some support, we do not have direct evidence. The challenge is to be able to distinguish between the ancestral populations that our study demonstrates in chicks, turtles, opossums, rodents, pig, and human and the presumed newly evolved subplate cells in eutherian mammals. For this the subplate cell types shall have to be established and relate to gene expression, connectivity, and functional properties in different species. These future experiments would help to answer if and how the subplate has been altered during evolution, and whether such alterations are related to and possibly drive changes in the size and complexity of the mammalian neocortex.

\section{ACKNOWLEDGMENTS}

We thank Eleanor Grant for her critical comments on an earlier version of this manuscript. This work was supported by the Medical Research Council to Zoltán Molnár (G0700377 and G00900901) and Fondecyt to Juan F. Montiel (3090062).

Evolutionary considerations. Cereb. Cortex 9, 783-791.

Aboitiz, F., and Montiel, J. (2007). Origin and evolution of the vertebrate telencephalon, with special reference to the mammalian neocortex. Adv. Anat. Embryol. Cell. Biol. 193, 1-112.

Aboitiz, F., Montiel, J., and Garcia, R. R. (2005). Ancestry of the mammalian preplate and its derivatives: evolutionary relicts or embryonic 
adaptations? Rev. Neurosci. 16, 359-376.

Allendoerfer, K. L., and Shatz, C. J. (1994). The subplate, a transient neocortical structure: its role in the development of connections between thalamus and cortex. Annu. Rev. Neurosci. 17, 185-218.

Anderson, S. A., Eisenstat, D. D., Shi, L., and Rubenstein, J. L. (1997). Interneuron migration from basal forebrain to neocortex: dependence on Dlx genes. Science 278, 474-476.

Antonini, A., and Shatz, C. J. (1990). Relation between putative transmitter phenotypes and connectivity of subplate neurons during cerebral cortical development. Eur. J. Neurosci. 2, 744-761.

Arias, M.S., Baratta, J.,Yu, J., and Robertson, R. T. (2002). Absence of selectivity in the loss of neurons from the developing cortical subplate of the rat. Brain Res. Dev. Brain Res. 139, 331-335.

Ashwell, K. W., Hardman, C., and Paxinos, G. (2004). The claustrum is not missing from all monotreme brains. Brain Behav. Evol. 64, 223-241.

Ayoub, A. E., and Kostović, I. (2009). New horizons for the subplate zone and its pioneering neurons. Cereb. Cortex 19, 1705-1707.

Bayer, S. A., and Altman, J. (1990). Development of layer I and the subplate in the rat neocortex. Exp. Neurol. 107, 48-62.

Brox, A., Puelles, L., Ferreiro, B., and Medina, L. (2003). Expression of the genes GAD67 and distal-less- 4 in the forebrain of Xenopus laevis confirms a common pattern in tetrapods. $J$. Comp. Neurol. 461, 370-393.

Butler, A. B., Molnár, Z., and Manger, P. R. (2002). Apparent absence of claustrum in monotremes: implications for forebrain evolution in amniotes. Brain Behav. Evol. 60, 230-240.

Bystron, I., Blakemore, C., and Rakic, P. (2008). Development of the human cerebral cortex: Boulder Committee revisited. Nat. Rev. Neurosci. 9, 110-122.

Carroll, R. L. (1988). Vertebrate Paleontology and Evolution. New York: Freeman Press.

Catalano, S. M., and Shatz, C. J. (1998). Activity-dependent cortical target selection by thalamic axons. Science 281, 559-562.

Cheung, A. F., Kondo, S., Abdel-Mannan, O., Chodroff, R. A., Sirey, T. M., Bluy, L. E., Webber, N., DeProto, J., Karlen, S. J., Krubitzer, L., Stolp, H. B., Saunders, N. R., and Molnár, Z. (2010). The subventricular zone is the developmental milestone of a 6-layered neocortex: comparisons in metatherian and eutherian mammals. Cereb. Cortex 20 , 1071-1081.
Cheung, A. F., Pollen, A. A., Tavare, A., DeProto, J., and Molnár, Z. (2007). Comparative aspects of cortical neurogenesis in vertebrates. J. Anat. 211, 164-176.

Chun, J. J., and Shatz, C. J. (1989). The earliest-generated neurons of the cat cerebral cortex: characterization by MAP2 and neurotransmitter immunohistochemistry during fetal life. J. Neurosci. 9, 1648-1667.

Cobas, A., Fairén, A., Alvarez-Bolado, G., and Sánchez, M. P. (1991). Prenatal development of the intrinsic neurons of the rat neocortex: a comparative study of the distribution of GABA-immunoreactive cells and the GABAA receptor. Neuroscience 40, 375-397.

Cobos, I., Puelles, L., and Martinez, S. (2001). The avian telencephalic subpallium originates inhibitory neurons that invade tangentially the pallium (dorsal ventricular ridge and cortical areas). Dev. Biol. 239, 30-45.

Connors, B. W., and Kriegstein, A. R. (1986). Cellular physiology of the turtle visual cortex: distinctive properties of pyramidal and stellate neurons. $J$. Neurosci. 6, 164-177.

Cordery, P., and Molnár, Z. (1999). Embryonic development of connections in turtle pallium. J. Comp. Neurol. 413, 26-54.

De Carlos, J.A., and O'Leary, D. D. (1992). Growth and targeting of subplate axons and establishment of major cortical pathways. J. Neurosci. 12, 1194-1211.

Del Rio, J. A., Martinez, A., Auladell, C., and Soriano, E. (2000). Developmental history of the subplate and developing white matter in the murine neocortex. Neuronal organization and relationship with the main afferent systems at embryonic and perinatal stages. Cereb. Cortex 10, 784-801.

Dupont, E., Hanganu, I. L., Kilb, W., Hirsch, S., and Luhmann, H. J. (2006). Rapid developmental switch in the mechanisms driving early cortical columnar networks. Nature 439, 79-83.

Finney, E. M., Stone, J. R., and Shatz, C. J. (1998). Major glutamatergic projection from subplate into visual cortex during development. J. Comp. Neurol. 398, 105-118.

Friauf, E., McConnell, S. K., and Shatz, C. J. (1990). Functional synaptic circuits in the subplate during fetal and early postnatal development of cat visual cortex. J. Neurosci. 10, 2601-2613.

Friauf, E., and Shatz, C. J. (1991). Changing patterns of synaptic input to subplate and cortical plate during development of visual cortex. $J$. Neurophysiol. 66, 2059-2071.
Ghosh, A., Antonini, A., McConnell, S. K., and Shatz, C. J. (1990). Requirement for subplate neurons in the formation of thalamocortical connections. Nature 347, 179-181.

Gibbs, R. A., Weinstock, G. M., Metzker, M. L., Muzny, D. M., Sodergren, E. J., Scherer, S., Scott, G., Steffen, D., Worley, K. C., Burch, P. E., Okwuonu, G., Hines, S., Lewis, L., DeRamo, C., Delgado, O., Dugan-Rocha, S., Miner, G., Morgan, M., Hawes, A. Gill, R., Celera, Holt, R. A., Adams, M. D., Amanatides, P. G., BadenTillson, H., Barnstead, M., Chin, S., Evans, C. A., Ferriera, S., Fosler C., Glodek, A., Gu, Z., Jennings, D., Kraft, C. L., Nguyen, T., Pfannkoch, C. M., Sitter, C., Sutton, G. G., Venter, J. C., Woodage, T., Smith, D., Lee, H. M., Gustafson, E., Cahill, P., Kana, A., Doucette-Stamm, L., Weinstock, K., Fechtel, K., Weiss, R. B., Dunn, D. M., Green, E.D., Blakesley, R. W., Bouffard, G. G., De Jong, P. J., Osoegawa, K. Zhu, B., Marra, M., Schein, J., Bosdet, I., Fjell, C., Jones, S., Krzywinski, M., Mathewson, C., Siddiqui, A., Wye, N., McPherson, J., Zhao, S., Fraser, C. M., Shetty, J., Shatsman, S., Geer, K., Chen, Y., Abramzon, S., Nierman, W. C., Havlak, P. H., Chen, R., Durbin, K. J., Egan, A., Ren, Y., Song, X. Z., Li, B., Liu, Y., Qin, X., Cawley, S., Worley, K. C., Cooney, A. J., D'Souza, L. M. Martin, K., Wu, J. Q., Gonzalez-Garay, M. L., Jackson, A. R., Kalafus, K. J., McLeod, M. P., Milosavljevic, A., Virk, D., Volkov, A., Wheeler, D. A., Zhang, Z., Bailey, J. A., Eichler, E. E., Tuzun, E., Birney, E., Mongin, E., UretaVidal, A., Woodwark, C., Zdobnov, E., Bork, P., Suyama, M., Torrents, D., Alexandersson, M., Trask, B. J., Young, J. M., Huang, H., Wang, H., Xing, H., Daniels, S., Gietzen, D., Schmidt, J., Stevens, K., Vitt, U., Wingrove, J. Camara, F., Mar Albà, M., Abril, J. F., Guigo, R., Smit, A., Dubchak, I., Rubin, E. M., Couronne, O., Poliakov, A., Hübner, N., Ganten, D., Goesele, C., Hummel, O., Kreitler, T., Lee, Y. A., Monti, J., Schulz, H., Zimdahl, H., Himmelbauer, H., Lehrach, H., Jacob, H. J., Bromberg, S., Gullings-Handley, J., Jensen-Seaman, M. I., Kwitek, A. E., Lazar, J., Pasko, D., Tonellato, P. J., Twigger, S., Ponting, C. P., Duarte, J.M., Rice, S., Goodstadt, L., Beatson, S. A., Emes, R. D., Winter, E. E., Webber, C., Brandt, P., Nyakatura, G., Adetobi, M., Chiaromonte, F., Elnitski, L., Eswara, P., Hardison, R. C., Hou, M., Kolbe, D. Makova, K., Miller, W., Nekrutenko, A., Riemer, C., Schwartz, S., Taylor, J., Yang, S., Zhang, Y., Lindpaintner, K., Andrews, T. D., Caccamo, M., Clamp, M., Clarke, L., Curwen, V., Durbin, R.
Eyras, E., Searle, S. M., Cooper, G. M., Batzoglou, S., Brudno, M., Sidow, A., Stone, E. A., Venter, J. C., Payseur, B. A. Bourque, G., López-Otín, C., Puente, X. S., Chakrabarti, K., Chatterji, S., Dewey, C., Pachter, L., Bray, N., Yap, V. B., Caspi, A., Tesler, G., Pevzner, P. A., Haussler, D., Roskin, K. M., Baertsch, R., Clawson, H., Furey, T. S., Hinrichs, A.S., Karolchik, D., Kent, W. J., Rosenbloom, K. R., Trumbower, H., Weirauch, M., Cooper, D. N., Stenson, P. D., Ma, B., Brent, M., Arumugam, M., Shteynberg, D., Copley, R. R., Taylor,M.S., Riethman,H., Mudunuri, U., Peterson, J., Guyer, M., Felsenfeld, A., Old, S., Mockrin, S., Collins, F., and Rat Genome Sequencing Project Consortium. (2004). Genome sequence of the Brown Norway rat yields insights into mammalian evolution. Nature 428, 493-521.

Hanashima, C., Molnár, Z., and Fishell, G. (2006). Building bridges to the cortex. Cell 125, 24-27.

Hanganu, I. L., Kilb, W., and Luhmann, H. J. (2001). Spontaneous synaptic activity of subplate neurons in neonatal rat somatosensory cortex. Cereb. Cortex $11,400-410$.

Hanganu, I. L., Kilb, W., and Luhmann, H. J. (2002). Functional synaptic projections onto subplate neurons in neonatal rat somatosensory cortex. $J$. Neurosci. 22, 7165-7176.

Harman, A. M., Eastough, N. J., and Beazley, L. D. (1995). Development of the visual cortex in a wallaby - phylogenetic implications. Brain Behav. Evol. 45, 138-152.

Heng, J. I., Moonen, G., and Nguyen, L. (2007). Neurotransmitters regulate cell migration in the telencephalon. Eur. J. Neurosci. 26, 537-546.

Higashi, S., Hioki, K., Kurotani, T., Kasim, N., and Molnár, Z. (2005). Functional thalamocortical synapse reorganization from subplate to layer IV during postnatal development in the reelerlike mutant rat (shaking rat Kawasaki). J. Neurosci. 25, 1395-1406.

Higashi, S., Molnár, Z., Kurotani, T., and Toyama, K. (2002). Prenatal development of neural excitation in rat thalamocortical projections studied by optical recording. Neuroscience 115 , 1231-1246.

Hoerder, A., Paulsen, O., and Molnár, Z (2006). Developmental changes in the dendritic morphology of subplate cells with known projections to the mouse cortex. FENS Abstract, 3, A156.10.

Hoerder-Suabedissen, A., Wang, W. Z., Lee, S., Davies, K. E., Goffinet, A. M., Rakic, S., Parnavelas, J., Reim, K., Nicolic, M., Paulsen, O., and Molnár, Z. (2009). Novel markers reveal subpopulations of subplate neurons in the 
murine cerebral cortex. Cereb. Cortex 19, 1738-1750.

Huntley, G. W., Hendry, S. H., Killackey, H. P., Chalupa, L. M., and Jones, E. G. (1988). Temporal sequence of neurotransmitter expression by developing neurons of fetal monkey visual cortex. Brain Res. 471, 69-96.

Jacobs, E. C., Campagnoni, C., Kampf, K., Reyes, S. D., Kalra, V., Handley, V., Xie, Y. Y., Hong-Hu, Y., Spreur, V., Fisher, R. S., and Campagnoni, A. T. (2007). Visualization of corticofugal projections during early cortical development in a tau-eGFP-transgenic mouse. Eur. J. Neurosci. 25, 17-30.

Jinno, S., Klausberger, T., Marton, L. F., Dalezios, Y., Roberts, J. D., Fuentealba, P., Bushong, E. A., Henze, D., Buzsaki, G., and Somogyi, P. (2007). Neuronal diversity in GABAergic long-range projections from the hippocampus. $J$. Neurosci. 27, 8790-8804.

Judas, M., Sestan, N., and Kostović, I. (1999). Nitrinergic neurons in the developing and adult human telencephalon: transient and permanent patterns of expression in comparison to other mammals. Microsc. Res. Tech. 45, 401-419.

Kanold, P. O., Kara, P., Reid, R. C., and Shatz, C. J. (2003). Role of subplate neurons in functional maturation of visual cortical columns. Science 301, 521-525.

Kanold, P. O., and Luhmann, H. J. (2010). The subplate and early cortical circuits. Annu. Rev. Neurosci. 33, 23-48.

Kanold, P. O., and Shatz, C. J. (2006). Subplate neurons regulate maturation of cortical inhibition and outcome of ocular dominance plasticity. Neuron 51, 627-638.

Kostović, I., and Jovanov-Milosević, N. (2008). Subplate zone of the human brain: historical perspective and new concepts. Coll. Antropol. 32, 3-8.

Kostovic', I., Judas, M., and Sedmak, G. (2010). Developmental history of the subplate zone, subplate neurons and interstitial white matter neurons: relevance for schizophrenia. Int. J. Dev. Neurosci. doi: 10.1016/j. ijdevneu.2010.09.005. [Epub ahead of print].

Kostović, I., and Molliver, M. E. (1974). A new interpretation of the laminar development of cerebral cortex: synaptogenesis in different layers of neopallium in the human fetus. Anat. Rec. 178, 395.

Kostović, I., and Rakic, P. (1980). Cytology and time of origin of interstitial neurons in the white matter in infant and adult human and monkey telencephalon. J. Neurocytol. 9, 219-242.

Kostović, I., and Rakic, P. (1990). Developmental history of the transient subplate zone in the visual and somatosensory cortex of the macaque monkey and human brain. J. Comp. Neurol. 297, 441-470.

Kriegstein, A., Noctor, S., and MartínezCerdeño, V. (2006). Patterns of neural stem and progenitor cell division may underlie evolutionary cortical expansion. Nat. Rev. Neurosci. 7, 883-890.

Künzle, H., and Ratke-Schuller, S. (2001). Cortical connections of the claustrum and subjacent cell groups in the hedgehog tenrec. Anat. Embryol. 203, 403-415.

Lauder, J. M., Han, V. K., Henderson, P., Verdoorn, T., and Towle, A. C. (1986). Prenatal ontogeny of the GABAergic system in the rat brain: an immunocytochemical study. Neuroscience 19, 465-493.

Lind, N. M., Moustgaard, A., Jelsing, J., Vajta, G., Cumming, P., and Hansen, A. K. (2007). The use of pigs in neuroscience: modeling brain disorders. Neurosci. Biobehav. Rev. 31, 728-751.

López-Bendito, G., and Molnár, Z. (2003). Thalamocortical development: how are we going to get there? Nat. Rev. Neurosci. 4, 276-289.

Lozsádi, D. A., Gonzales-Soriano, J., and Guillery, R.W. (1996). The course and termination of corticothalamic fibres arising in the visual cortex of the rat. Eur. J. Neurosci. 8, 2416-2427.

Luhmann, H. J., Kilb, W., and HanganuOpatz, I. L. (2009). Subplate cells: amplifiers of neuronal activity in the developing cerebral cortex. Front. Neuroanat. 3:19. doi: 10.3389/ neuro.05.019.2009

Luhmann, H. J., Reiprich, R. A., Hanganu, I. L., and Kilb, W. (2000). Cellular physiology of the neonatal rat cerebral cortex: intrinsic membrane properties, sodium and calcium currents. J. Neurosci. Res. 62, 574-584.

Lukaszewicz, A., Savatier, P., Cortay, V., Giroud, P., Huissoud, C., Berland, M., Kennedy, H., and Dehay, C. (2005). G1 phase regulation, area-specific cell cycle control, and cytoarchitectonics in the primate cortex. Neuron 47, 353-364.

Lund, R. D., and Mustari, M. J. (1977). Development of the geniculocortical pathways in rats. J. Comp. Neurol. 173, 289-306.

Luskin, M. B., Pearlman, A. L., and Sanes, J. R. (1988). Cell lineage in the cerebral cortex of the mouse studied in vivo and in vitro with a recombinant retrovirus. Neuron 1, 635-647.

Luskin, M. B., and Shatz, C. J. (1985). Studies of the earliest generated cells of the cat's visual cortex: cogeneration of subplate and marginal zones. J. Neurosci. 5, 1062-1075.

Mannen, H., and Li, S.S. (1999). Molecular evidence for a clade of turtles. $\mathrm{Mol}$. Phylogenet. Evol. 13, 144-148.
Marín, O., and Rubenstein, J. L. (2003). Cell migration in the forebrain. Annu. Rev. Neurosci. 26, 441-483.

Marín-Padilla, M. (1971). Early prenatal ontogenesis of the cerebral cortex (neocortex) of the cat (Felis domestica). A Golgi study. I. The primordial neocortical organization. Z. Anat. Entwicklungsgesch. 134, 117-1145.

Mark, R. F., and Marotte, L. R. (1992). Australian marsupials as models for the developing mammalian visual system. Trends Neurosci. 15, 51-57.

McConnell, S. K., Ghosh, A., and Shatz, C. J. (1989). Subplate neurons pioneer the first axon pathway from the cerebral cortex. Science 245, 978-982.

McKellar, C. E., and Shatz, C. J. (2009). Synaptogenesis in purified cortical subplate neurons. Cereb. Cortex 19, 1723-1737.

Medina, L., Legaz, I., Gonzalez, G., De Castro, F., Rubenstein, J. L., and Puelles, L. (2004). Expression of Dbx1, Neurogenin 2, Semaphorin 5A, Cadherin 8, and Emx1 distinguish ventral and lateral pallial histogenetic divisions in the developing mouse claustroamygdaloid complex. J. Comp. Neurol. 474, 504-523.

Métin, C., Alvarez, C., Moudoux, D., Vitalis, T., Pieau, C., and Molnár, Z. (2007). Conserved pattern of tangential neuronal migration during forebrain development. Development 134, 2815-2827.

Métin, C., Vallee, R. B., Rakic, P., and Bhide, P. G. (2008). Modes and mishaps of neuronal migration in the mammalian brain. J. Neurosci. 28 , 11746-11752.

Meyer, G. (2007). Genetic control of neuronal migrations in human cortical development. Adv. Anat. Embryol. Cell Biol. 189, 1-111.

Meyer, G., Wahle, P., CastaneyraPerdomo, A., and Ferres-Torres, R. (1992). Morphology of neurons in the white matter of the adult human neocortex. Exp. Brain Res. 88, 204-212.

Mitrofanis, J., and Guillery, R. W. (1993). New views of the thalamic reticular nucleus in the adult and the developing brain. Trends Neurosci. 16, 240-250.

Molnár, Z. (2000a). Conserved developmental algorithms during thalamocortical circuit formation in mammals and reptiles. Novartis Found. Symp. 228, 148-166; discussion 166-172.

Molnár, Z. (2000b). Development and evolution of thalamocortical interactions. Eur. J. Morphol. 38, 313-320.

Molnár, Z., Adams, R., Goffinet, A. M., and Blakemore, C. (1998). The role of the first postmitotic cortical cells in the development of thalamocorti- cal innervation in the reeler mouse. J. Neurosci. 18, 5746-5765.

Molnár, Z., and Blakemore, C. (1995). How do thalamic axons find their way to the cortex? Trends Neurosci. 18, 389-397.

Molnár, Z., and Butler, A. B. (2002). The corticostriatal junction: a crucial region for forebrain development and evolution. Bioessays 24, 530-541.

Molnár, Z., and Cordery, P. (1999). Connections between cells of the internal capsule, thalamus, and cerebral cortex in embryonic rat. J. Comp. Neurol. 413, 1-25.

Molnár, Z., Hoerder-Suabedissen, A., Wang, W. Z., DeProto, J., Davies, K., Lee, S., Jacobs, E. C., Campagnoni, A. T., Paulsen, O., Pinon, M. C., and Cheung, A. F. (2007). Genes involved in the formation of the earliest cortical circuits. Novartis Found. Symp. 288, 212-224; discussion 224-229, 276-281.

Molnár, Z., Métin, C., Stoykova, A., Tarabykin, V., Price, D. J., Francis, F., Meyer, G., Dehay, C., and Kennedy, H. (2006). Comparative aspects of cerebral cortical development. Eur. J. Neurosci. 23, 921-934.

Moore, A. R., Filipovic, R., Mo, Z., Rasband, M.N.,Zecevic, N., and Antic, S. D. (2009). Electrical excitability of early neurons in the human cerebral cortex during the second trimester of gestation. Cereb. Cortex 19, 1795-1805.

Mrzljak, L., Uylings, H. B., Kostović, I., and Van Eden, C. G. (1988). Prenatal development of neurons in the human prefrontal cortex: I. A qualitative Golgi study. J. Comp. Neurol. 271, 355-386.

Nacher, J., Ramirez, C., Molowny, A., and Lopez-Garcia, C. (1996). Ontogeny of somatostatin immunoreactive neurons in the medial cerebral cortex and other cortical areas of the lizard Podarcis hispanica. J. Comp. Neurol. 374, 118-135.

Nielsen, K. B., Kruhoffer, M., Holm, I. E., Jorgensen, A. L., and Nielsen, A. L. (2010a). Identification of genes differentially expressed in the embryonic pig cerebral cortex before and after appearance of gyration. BMC Res. Notes 3, 127. doi: 10.1186/1756-0500-3-127

Nielsen, K. B., Sondergaard, A., Johansen, M. G., Schauser, K., Vejlsted, M., Nielsen, A. L., Jorgensen, A. L., and Holm, I. E. (2010b). Reelin expression during embryonic development of the pig brain. $B M C$ Neurosci. 11, 75. doi: http://dx.doi. org/10.1186/1471-2202-11-75

Oeschger, F. M., Wang, W. Z., Lee, S., Arbones, M., and Molnár, Z. (2010). Gene expression profiling of the embryonic day 15 murine subplate 
using laser capture microdissection and microarray. FENS Abstr. 5, 101.24.

Ozaki, H. S., and Wahlsten, D. (1998). Timing and origin of the first cortical axons to project through the corpus callosum and the subsequent emergence of callosal projection cells in mouse. J. Comp. Neurol.400, 197-206.

Parnavelas, J. G. (2000). The origin and migration of cortical neurones: new vistas. Trends Neurosci. 23, 126-131.

Pereira, S. L., and Baker, A. J. (2006). A mitogenomic timescale for birds detects variable phylogenetic rates of molecular evolution and refutes the standard molecular clock. Mol. Biol. Evol. 23, 1731-1740.

Perkins, L., Hughes, E., Srinivasan, L., Allsop, J., Glover, A., Kumar, S., Fisk, N., and Rutherford, M. (2008). Exploring cortical subplate evolution using magnetic resonance imaging of the fetal brain. Dev. Neurosci. 30, 211-220.

Piñon, M. C., Jethwa, A., Jacobs, E., Campagnoni, A., and Molnár, Z. (2009). Dynamic integration of subplate neurons into the cortical barrel field circuitry during postnatal development in the Golli-tau-eGFP (GTE) mouse. J. Physiol. 587, 1903-1915.

Pleasure, S. J., Anderson, S., Hevner, R., Bagri, A., Marin, O., Lowenstein, D. H., and Rubenstein, J. L. (2000). Cell migration from the ganglionic eminences is required for the development of hippocampal GABAergic interneurons. Neuron 28, 727-740.

Price, D. J., Aslam, S., Tasker, L., and Gillies, K. (1997). Fates of the earliest generated cells in the developing murine neocortex. J. Comp. Neurol. $377,414-422$.

Rakic, P. (1977). Genesis of the dorsal lateral geniculate nucleus in the rhesus monkey: site and time of origin, kinetics of proliferation, routes of migration and pattern of distribution of neurons. J. Comp. Neurol. 176, 23-52.

Rakic, P., and Caviness, V. S. Jr. (1995). Cortical development: view from neurological mutants two decades later. Neuron 14, 1101-1104.

Rakic, S., Davis, C., Molnár, Z., Nikolic, M., and Parnavelas, J. G. (2006). Role of $\mathrm{p} 35 / \mathrm{Cdk} 5$ in preplate splitting in the developing cerebral cortex. Cereb. Cortex 16(Suppl. 1), i35-i45.

Reep, R. L. (2000). Cortical layer VII and persistent subplate cells in mammalian brains. Brain Behav. Evol. 56, 212-234.

Reep, R. L., and Goodwin, G. S. (1988). Layer VII of rodent cerebral cortex. Neurosci. Lett. 90, 15-20.
Reiner, A. (1991). A comparison of neurotransmitter-specific and neuropeptide-specific neuronal cell types present in the dorsal cortex in turtles with those present in the isocortex in mammals: implications for the evolution of isocortex. Brain Behav. Evol. 38, 53-91.

Ribak, C. E., Seress, L., Peterson, G. M., Seroogy, K. B., Fallon, J. H., and Schmued, L. C. (1986). A GABAergic inhibitory component within the hippocampal commissural pathway. J. Neurosci. 6, 3492-3498.

Rickmann, M., Chronwall, B. M., and Wolff, J. R. (1977). On the development of non-pyramidal neurons and axons outside the cortical plate: the early marginal zone as a pallial anlage. Anat. Embryol. 151, 285-307.

Rieppel, O., and Reisz, R. R. (1999). The origin and early evolution of turtles. Annu. Rev. Ecol. Syst. 30, 1-22.

Schiffmann, S., Campistron, G., Tugendhaft, P., Brotchi, J., Flament-Durand, J., Geffard, M., and Vanderhaeghen, J. J. (1988). Immunocytochemical detection of GABAergic nerve cells in the human temporal cortex using a direct gammaaminobutyric acid antiserum. Brain Res. 442, 270-278.

Shatz, C. J., and Rakic, P. (1981). The genesis of efferent connections from the visual cortex of the fetal rhesus monkey. J. Comp. Neurol. 196, 287-307.

Smart, I. H., Dehay, C., Giroud, P., Berland, M., and Kennedy, H. (2002). Unique morphological features of the proliferative zones and postmitotic compartments of the neural epithelium giving rise to striate and extrastriate cortex in the monkey. Cereb. Cortex 12, 37-53.

Somogyi, P., Cowey, A., Halasz, N., and Freund, T. F. (1981). Vertical organization of neurones accumulating 3 H-GABA in visual cortex of rhesus monkey. Nature 294, 761-763.

Somogyi, P., Hodgson, A. J., Smith, A. D., Nunzi, M. G., Gorio, A., and Wu, J. Y. (1984). Different populations of GABAergic neurons in the visual cortex and hippocampus of cat contain somatostatin- or cholecystokininimmunoreactive material. J. Neurosci. 4, 2590-2603.

Srivastava, U. C., Maurya, R. C., and Chand, P. (2009). Cyto-architecture and neuronal types of the dorsomedial cerebral cortex of the common Indian wall lizard, Hemidactylus flaviviridis. Arch. Ital. Biol. 147, 21-35.

Supèr, H., and Uylings, H. B. (2001). The early differentiation of the neocortex: a hypothesis on neocortical evolution. Cereb. Cortex 11, 1101-1109.

Swanson, L. W. (2000). Cerebral hemisphere regulation for motivated behavior. Brain Res. 886, 113-164.

Tarabykin, V., Stoykova, A., Usman, N., and Gruss, P. (2001). Cortical upper layer neurons derive from the subventricular zone as indicated by Svet1 gene expression. Development 128, 1983-1993.

Tomioka, R., and Rockland, K. S. (2007). Long-distance corticocortical GABAergic neurons in the adult monkey white and gray matter. J. Comp. Neurol. 505, 526-538.

Torres-Reveron, J., and Friedlander, M. J. (2007). Properties of persistent postnatal cortical subplate neurons. J. Neurosci. 27, 9962-9974.

Toth, K., and Freund, T. F. (1992). Calbindin D28k-containing nonpyramidal cells in the rat hippocampus: their immunoreactivity for GABA and projection to the medial septum. Neuroscience 49, 793-805.

Uylings, H. B., and Delalle, I. (1997). Morphology of neuropeptide Y-immunoreactive neurons and fibers in human prefrontal cortex during prenatal and postnatal development. J. Comp. Neurol. 379, 523-540.

Valverde, F., De Carlos, J. A., and LopezMascaraque, L. (1995). Time of origin and early fate of preplate cells in the cerebral cortex of the rat. Cereb. Cortex 5, 483-493.

Valverde, F., Facal-Valverde, M. V., Santacana, M., and Heredia, M. (1989). Development and differentiation of early generated cells of sublayer $\mathrm{VIb}$ in the somatosensory cortex of the rat: a correlated Golgi and autoradiographic study. J. Comp. Neurol. 290, 118-140.

Wahle, P., and Meyer, G. (1987). Morphology and quantitative changes of transient NPY-ir neuronal populations during early postnatal development of the cat visual cortex. J. Comp. Neurol. 261, 165-192.

Wang, W. Z., Hoerder-Suabedissen, A., Oeschger, F. M., Bayatti, N., Ip, B. K., Lindsay, S., Supramaniam, V., Srinivasan, L., Rutherford, M., Mollgard, K., Clowry, G. J., and Molnár, Z. (2010). Subplate in the developing cortex of mouse and human. J. Anat. 217, 368-380.

Wang, W. Z., Oeschger, F. M., Montiel, J. F., García-Moreno, F., HoerderSuabedissen, A., Krubitzer, L., Ek, C. J., Saunders, N., Reim, K., Villalón, A., and Molnár, Z. (2011). Comparative aspects of subplate zone studied with gene expression in sauropsids and mammals. Cereb. Cortex. doi: 10.1093/ cercor/bhq278. [Epub ahead of print].

Winer, J. A., and Larue, D. T. (1989). Populations of GABAergic neurons and axons in layer I of rat auditory cortex. Neuroscience 33, 499-515.

Wonders, C. P., and Anderson, S. A. (2006). The origin and specification of cortical interneurons. Nat. Rev. Neurosci. 7, 687-696.

Woo, T. U., Beale, J. M., and Finlay, B. L. (1991). Dual fate of subplate neurons in a rodent. Cereb. Cortex 5, 433-443.

Woo, T. U., and Finlay, B. L. (1996). Cortical target depletion and ingrowth of geniculocortical axons: implications for cortical specification. Cereb. Cortex $6,457-469$.

Yan, X. X., Garey, L. J., and Jen, L. S. (1996). Prenatal development of NADPH-diaphorase-reactive neurons in human frontal cortex. Cereb. Cortex 6, 737-745.

Zardoya, R., and Meyer, A. (2001). The evolutionary position of turtles revised. Naturwissenschaften 88 , 193-200.

Zhao, C., Kao, J. P., and Kanold, P. O. (2009). Functional excitatory microcircuits in neonatal cortex connect thalamus and layer 4. J. Neurosci. 29, 15479-15488.

Conflict of Interest Statement: The authors declare that the research was conducted in the absence of any commercial or financial relationships that could be construed as a potential conflict of interest.

Received: 15 December 2010; paper pending published: 25 January 2011; accepted: 25 March 2011; published online: 07 April 2011.

Citation: Montiel JF, Wang WZ, Oeschger FM, Hoerder-Suabedissen A, Tung WL, García-Moreno F, Holm IE, Villalón A and Molnár Z (2011) Hypothesis on the dual origin of the mammalian subplate. Front. Neuroanat. 5:25. doi: 10.3389/ fnana.2011.00025

Copyright $\odot 2011$ Montiel, Wang, Oeschger, Hoerder-Suabedissen, Tung, GarcíaMoreno, Holm, Villalón and Molnár. This is an open-access article subject to a nonexclusive license between the authors and Frontiers Media SA, which permits use, distribution and reproduction in other forums, provided the original authors and source are credited and other Frontiers conditions are complied with. 